\title{
Evolution of treatment and a detailed analysis of occlusion, recurrence, and clinical outcomes in an endovascular library of 260 dural arteriovenous fistulas
}

\author{
Bradley A. Gross, MD, Felipe C. Albuquerque, MD, Karam Moon, MD, and \\ Cameron G. McDougall, MD \\ Department of Neurosurgery, Barrow Neurological Institute, St. Joseph's Hospital and Medical Center, Phoenix, Arizona
}

OBJECTIVE Many small series and technical reports chronicle the evolution of endovascular techniques for cranial dural arteriovenous fistulas (dAVFs) over the past 3 decades, but reports of large patient series are lacking. The authors provide a thorough analysis of clinical and angiographic outcomes across a large patient cohort.

METHODS The authors reviewed their endovascular database from January 1996 to September 2015 to identify patients harboring cranial dAVFs who were treated initially with endovascular approaches. They extracted demographic, presentation, angiographic, detailed treatment, and long-term follow-up data, and they evaluated natural history, initial angiographic occlusion, complications, recurrence, and symptomatic resolution rates.

RESULTS Across a cohort of 251 patients with 260 distinct dAVFs, the overall initial angiographic occlusion rate was $70 \%$; recurrence or occult residual lesions were seen on subsequent angiography in $3 \%$ of cases. The overall complication rate was $8 \%$, with permanent neurological complications occurring in $3 \%$ of cases. Among 102 patients with dAVFs without cortical venous reflux, rates of resolution/improvement of pulsatile tinnitus and ocular symptoms were $79 \%$ and $78 \%$, respectively. Following the introduction of Onyx during the latter half of the study period, the number of treated dAVFs doubled; the initial angiographic occlusion rate increased significantly from $60 \%$ before the use of Onyx to $76 \%$ after $(p=0.01)$. In addition, during the latter period compared with the pre-Onyx period, the rate of dAVFs obliterated via a transarterial-only approach was significantly greater ( $43 \%$ vs $23 \%, p=0.002)$, as was the number of dAVFs obliterated via a single arterial pedicle ( $29 \%$ vs $11 \%, p=0.002)$.

CONCLUSIONS Overall, in the Onyx era, the rate of initial angiographic occlusion was approximately $80 \%$, as was the rate of meaningful clinical improvement in tinnitus and/or ocular symptoms after initial endovascular treatment of cranial dAVFs.

https://thejns.org/doi/abs/10.3171/2016.5.JNS16331

KEY WORDS arteriovenous fistula; dAVF; dural arteriovenous fistula; embolization; endovascular; Onyx; NBCA; $\mathrm{N}$-butyl cyanoacrylate; interventional neurosurgery; vascular disorders

$\mathrm{D}$ URAL arteriovenous fistulas (dAVFs) are formidable vascular lesions; patients with these lesions may have a panoply of clinical presentations. ${ }^{3,7}$, 13,18,23,31,35,38 The complex anatomical pathology of dAVFs catalyzed the evolution of creative endovascular treatment strategies. ${ }^{11,12,14,16,24,37,39}$ This evolution was punctuated by the advancement of transvenous approaches in the late $1980 \mathrm{~s}^{14}$ and by the introduction of Onyx (Covidien) in the transarterial (and transvenous) treatment armamentarium approximately a decade ago..$^{16,24,25,27,29,37,39}$ Despite the preponderance of technical reports and small case series describing the endovascular treatment of dAVFs, $, 2,25,27,29,34,36,39$ there is a paucity of reports describing substantial series of patients., ${ }^{4,0,26,28}$ We sought to evaluate the natural history, initial angiographic occlusion rates, recurrence rates, and symptomatic improvement rates across a large series of patients. Armed with a fairly large patient cohort, we also sought to evaluate these parameters across more meaning-

ABBREVIATIONS dAVF = dural arteriovenous fistula; $\mathrm{ECA}=$ external carotid artery; $\mathrm{MMA}=$ middle meningeal artery; $\mathrm{NBCA}=\mathrm{N}$-butyl cyanoacrylate; $\mathrm{NHND}=$ nonhemorrhagic neurological deficit.

SUBMITTED February 8, 2016. ACCEPTED May 27, 2016.

INCLUDE WHEN CITING Published online September 2, 2016; DOI: 10.3171/2016.5.JNS16331. 

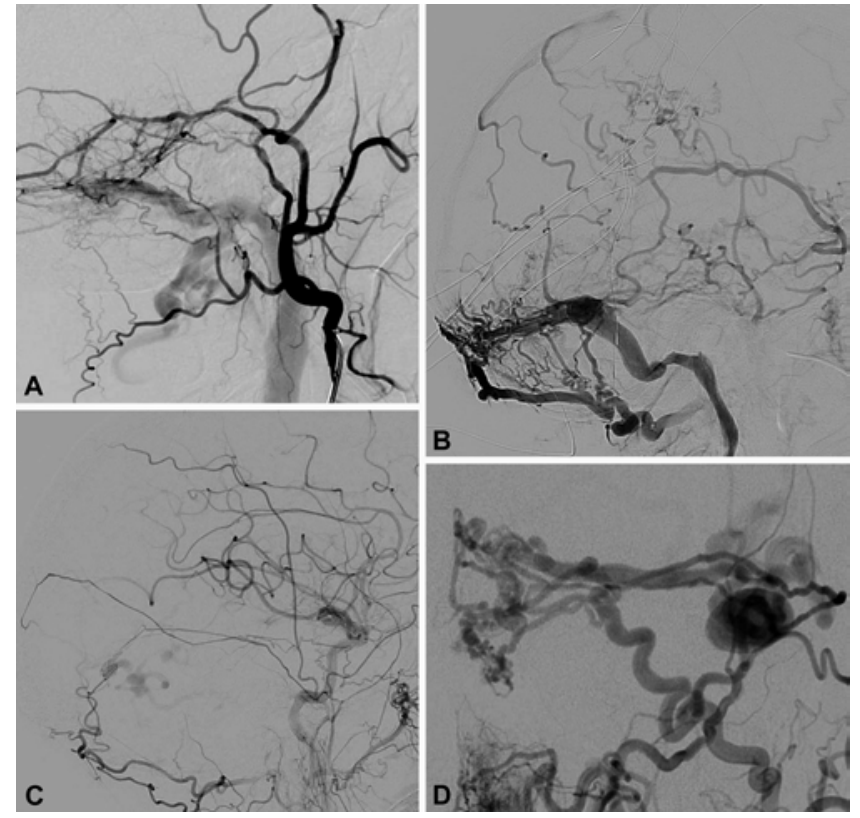

FIG. 1. Sample dAVFs by Djindjian type. A: Lateral projection of an ECA angiogram demonstrating a transverse/sigmoid dAVF supplied by MMA and transosseous occipital artery branches with antegrade sinus drainage (Djindjian Type I, Borden-Shucart Type I, Cognard Type I). B: Lateral projection of an ECA angiogram demonstrating a transverse-sigmoid dAVF supplied by the MMA and transosseous occipital artery branches with retrograde cortical venous reflux (Djindjian Type II, Borden-Shucart Type II, Cognard Type IIb). C: Lateral projection of the late phase of a common carotid artery angiogram demonstrating a tentorial dAVF supplied by the MMA and occipital artery branches with direct cortical venous drainage (Djindjian Type III, Borden-Shucart Type III, Cognard Type III). D: Anteroposterior projection of an ECA angiogram demonstrating a tentorial dAVF supplied by the MMA and occipital artery branches with cortical venous drainage with ectasia (Djindjian Type IV, Borden-Shucart Type III, Cognard Type IV).

ful subgroup analyses - stratification by dAVF drainage pattern and location.

\section{Methods}

We performed a retrospective analysis of a prospectively maintained endovascular patient database to identify all patients with cranial dAVFs treated endovascularly from January 1996 to September 2015. We excluded patients with spinal dAVFs, children with dural sinus malformations or infantile dural arteriovenous shunts, and patients managed with surgery or radiosurgery as the initial treatment approach. We extracted patient demographic information and symptoms at clinical presentation. For each dAVF, we extracted detailed angiographic information, including specific feeding arteries, venous drainage pattern, and the presence of venous ectasia. Because we do not always inject bilateral vertebral arteries prior to dAVF treatment, we could not accurately estimate the frequency of posterior meningeal artery dAVF supply.

Venous drainage was classified on the basis of the original Djindjian classification scheme ${ }^{12}$ (Fig. 1, Table 1). This scheme parses out the presence of both cortical venous reflux and venous ectasia, ${ }^{12} 2$ recognized risk factors for dAVF aggressiveness. ${ }^{8,13}$ In our cohort, dAVFs were considered to be multiple lesions only when drainage was into a different venous sinus system or cortical vein; multiplehole fistulas with a common draining vein/sinus were considered a single entity. We noted the interval occurrence of new nonhemorrhagic neurological deficits (NHNDs) or hemorrhage and the time between initial clinical presentation and initiation of endovascular treatment to help define untreated lesion natural history. In addition to procedural complications, we noted treatment information, including which pedicles were embolized, the embolization agent, and the initial angiographic results. Angiographic and clinical follow-up results were noted along with the rates of radiographic recurrence and specific information on retreatment approaches.

Categorical variable comparisons were performed with the Fisher exact test. Results were considered statistically significant for $\mathrm{p}$ values $<0.05$.

\section{General Embolization Technique}

There has been considerable evolution in treatment technique over the 20-year study period. Our current practice includes placing all patients under general endotracheal anesthesia with neurophysiological monitoring (somatosensory evoked potentials and electroencephalography). Procedures are begun with arterial access via a 6-F sheath and performance of diagnostic angiography,

TABLE 1. Classification of cranial dAVFs

\begin{tabular}{cccl}
\hline Type & \multicolumn{1}{c}{ Djindjian-Merland* } & Borden-Shucart & \multicolumn{1}{c}{ Cognard-Merland $\neq$} \\
\hline I & Drainage into a venous sinus & Drainage into a venous sinus & Antegrade drainage into a venous sinus \\
\hline II & $\begin{array}{c}\text { Drainage into a venous sinus w/ } \\
\text { cortical venous reflux }\end{array}$ & $\begin{array}{c}\text { Drainage into a venous sinus w/ } \\
\text { cortical venous reflux }\end{array}$ & $\begin{array}{l}\text { Ila: Drainage into a venous sinus w/ retrograde flow in the sinus } \\
\text { Ilb: Drainage into a venous sinus w/ cortical venous reflux } \\
\text { Ila+b: Combination }\end{array}$ \\
\hline III & Direct cortical venous drainage & Direct cortical venous drainage & Direct cortical venous drainage \\
\hline IV & $\begin{array}{c}\text { Direct cortical venous drainage } \\
\text { w/ venous ectasia }\end{array}$ & Direct cortical venous drainage w/ venous ectasia \\
\hline V & & & Spinal perimedullary drainage \\
\hline
\end{tabular}

* Djindjian and Merland, 1978.

$\dagger$ Borden et al., 1995.

$\ddagger$ Cognard et al., 1995. 
which is focused on a search for external carotid artery (ECA) pedicles, most commonly the middle meningeal artery (MMA) or occipital artery, or expected internal carotid artery feeding pedicles (as in cases of anterior cranial fossa dAVFs). Patients undergo systemic anticoagulation with heparin. If a reasonable pedicle is disclosed on carotid branch injections, we rarely inject the vertebral arteries prior to embolization as the posterior meningeal artery is rarely a "first choice" arterial pedicle for embolization. For added support, we often attempt to employ triaxial systems with dimethyl sulfoxide and glue-compatible microcatheters. Before embolization, superselective angiography via the microcatheter is performed to evaluate proximity to the fistula point, the presence of potential anastomoses, and the rate of arteriovenous shunting. Our general transarterial embolization agent of choice is Onyx; however, if access to a high-flow fistulous pouch is achieved transarterially, we might employ $N$-butyl cyanoacrylate (NBCA) instead. For most cavernous dAVFs and for cases in which transarterial access within reasonable proximity of the fistula point cannot be achieved or transarterial embolization fails to cast the fistula point, venous access in the common femoral vein with a 6-F sheath is then obtained in an attempt to perform transvenous coil or Onyx embolization. We may also use transvenous access to place a balloon in a venous sinus to mitigate the risk of nontarget embolization of the sinus (Fig. 2). For cavernous dAVFs, we most often perform transvenous coil embolization and supplement with Onyx when coiling does not entirely obliterate the fistula. At the conclusion of the procedure, control angiography is performed to confirm that no further arteriovenous shunting is occurring. Bilateral vertebral artery injections are then performed to ensure that there is no further supply from posterior meningeal/muscular branches when applicable. The patient is extubated and observed in the intensive care unit overnight. Postoperative imaging is performed only when new concerning symptoms develop (severe headache or neurological deficit). Patients are often discharged on the 1st postembolization day. We perform angiographic follow-up at 3-4 months postprocedure for local patients and recommend such follow-up for distant referral patients.

\section{Results}

\section{Demographics and Treatment Approaches}

Across a cohort of 251 patients with 260 distinct dAVFs, the mean age was $58 \pm 16$ years $( \pm \mathrm{SD})$, and there was a male predominance (1.5:1; 60\% males) (Table 2). Nineteen dAVFs occurred after a definite history of cranial trauma (7\%). Among the $260 \mathrm{dAVFs}$, presentation was incidental in $11 \%$, and with pulsatile tinnitus in 39\%, ocular symptoms in $27 \%$, NHNDs (symptomatic venous hypertension) in $15 \%$, and intracranial hemorrhage in $15 \%$. The most common dAVF location was along the transverse and/or sigmoid sinus (33\%). Arterial supply most commonly included the MMA (74\%). Occipital artery supply was seen in $56 \%$ of dAVFs, tentorial artery supply in $31 \%$, and ascending pharyngeal artery supply in $25 \%$. Transarterial approaches were the most common (55\%), with the MMA ( $56 \%$ of cases) and occipital artery ( $24 \%$ of cases) the most commonly embolized pedicles.
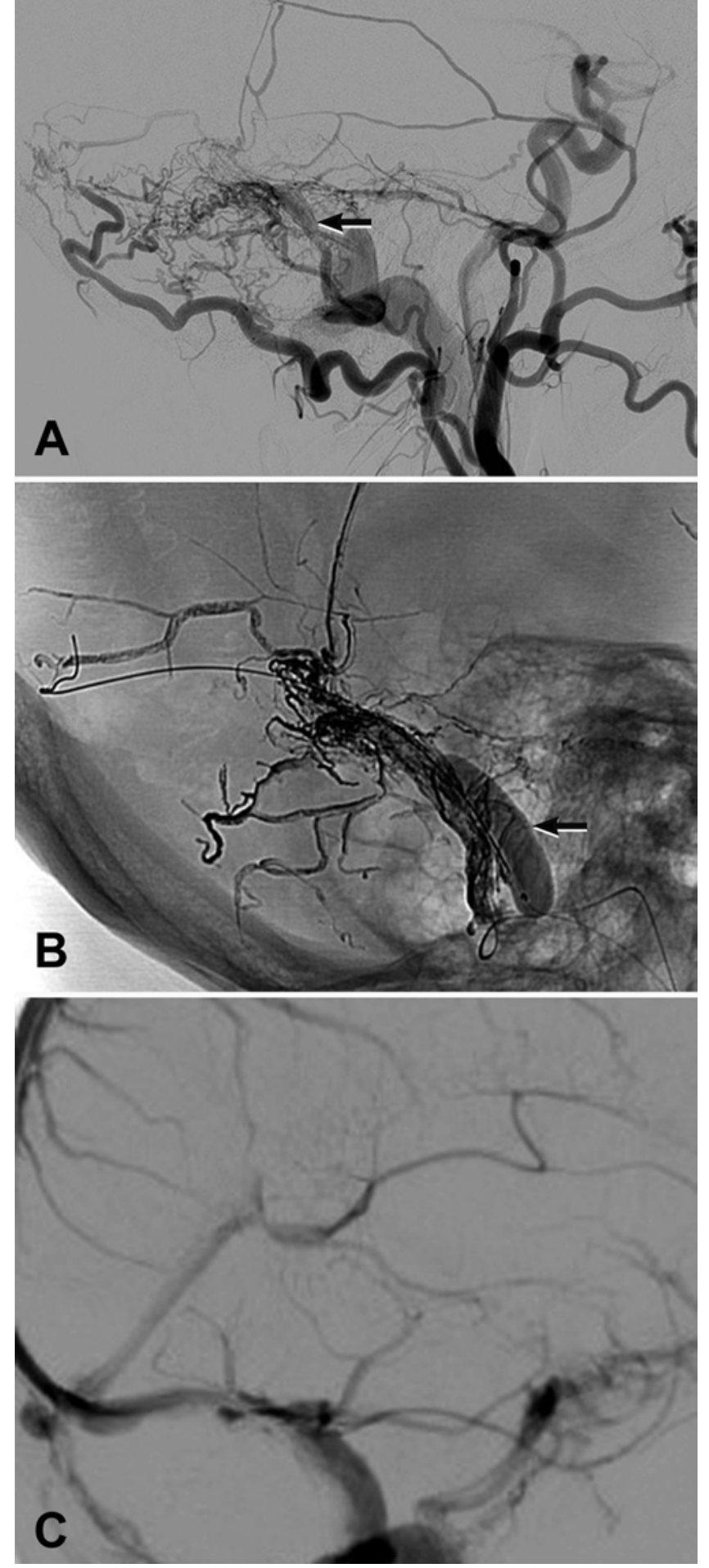

FIG. 2. Lateral view of an ECA injection demonstrating a sigmoid sinus dAVF supplied by MMA and occipital artery branches with a parallel venous pouch (arrow, A). Supply from the tentorial artery is also seen from reflux into the internal carotid artery. The parent sigmoid sinus is protected by inflation of a balloon in the sinus (arrow) during combined single-pedicle MMA simultaneous transarterial and transvenous Onyx embolization (B: lateral skull radiograph demonstrating a casted dAVF vein). Sigmoid sinus outflow is preserved (C: lateral view of venous phase of internal carotid artery angiogram). 
TABLE 2. Demographic, presentation, dAVF angiographic, and treatment information for 260 dAVFs among 251 patients: overall and stratified by dAVF venous drainage*

\begin{tabular}{|c|c|c|c|c|}
\hline Variable & Overall $(n=260)$ & Type I $(n=102)$ & Type II $(n=72)$ & Type III/IV $(n=86)$ \\
\hline Mean patient age (SD), years & $58(16)$ & $56(15)$ & $60(16)$ & $58(15)$ \\
\hline Male/female ratio (\% male) & $1.5: 1.0(60 \%)$ & $1.0: 1.0(50 \%)$ & 1.5:1.0 (60\%) & $3.1: 1.0(76 \%)$ \\
\hline \multicolumn{5}{|l|}{ Presentation } \\
\hline Incidental & $28(11 \%)$ & 0 & $4(6 \%)$ & $24(28 \%)$ \\
\hline Tinnitus & $101(39 \%)$ & $62(61 \%)$ & $33(46 \%)$ & $6(7 \%)$ \\
\hline Ocular symptoms & $69(27 \%)$ & $43(42 \%)$ & $23(32 \%)$ & $3(3 \%)$ \\
\hline NHND & $38(15 \%)$ & 0 & $15(21 \%)$ & $23(27 \%)$ \\
\hline Hemorrhage & $39(15 \%)$ & 0 & $8(11 \%)$ & $31(36 \%)$ \\
\hline \multicolumn{5}{|l|}{ dAVF location } \\
\hline Anterior cranial fossa & $6(2 \%)$ & 0 & 0 & $6(7 \%)$ \\
\hline Superior sagittal sinus & $32(12 \%)$ & $2(2 \%)$ & $4(6 \%)$ & $26(30 \%)$ \\
\hline Sphenoparietal sinus & $5(2 \%)$ & 0 & 0 & $5(6 \%)$ \\
\hline Cavernous sinus & $59(23 \%)$ & $41(40 \%)$ & $18(25 \%)$ & 0 \\
\hline Transverse \&/or sigmoid sinus & $85(33 \%)$ & $43(42 \%)$ & $39(54 \%)$ & $3(3 \%)$ \\
\hline Torcular & $15(6 \%)$ & $5(5 \%)$ & $10(14 \%)$ & 0 \\
\hline Tentorial/petrosal & $47(18 \%)$ & $1(1 \%)$ & 0 & $46(53 \%)$ \\
\hline Marginal sinus & $11(4 \%)$ & $10(10 \%)$ & $1(1 \%)$ & 0 \\
\hline \multicolumn{5}{|l|}{ Treatment approach } \\
\hline Transarterial w/o transvenous & $142(55 \%)$ & $31(30 \%)$ & $35(49 \%)$ & $76(88 \%)$ \\
\hline MMA embolization & $145(56 \%)$ & $32(31 \%)$ & $45(63 \%)$ & $68(79 \%)$ \\
\hline Transvenous w/o transarterial & $63(24 \%)$ & $42(41 \%)$ & $18(25 \%)$ & $3(3 \%)$ \\
\hline Transarterial \& transvenous & $52(20 \%)$ & $26(25 \%)$ & $19(26 \%)$ & $7(8 \%)$ \\
\hline Direct puncture in angiography suite (no craniotomy) & $14(5 \%)$ & $10(10 \%)$ & $4(6 \%)$ & 0 \\
\hline \multicolumn{5}{|l|}{ Occlusion } \\
\hline Initial angiographic occlusion rate & $183(70 \%)$ & $71(70 \%)$ & $44(61 \%)$ & $68(79 \%)$ \\
\hline Spontaneous thrombosis after partial treatment & $6 / 77(8 \%)$ & $4 / 31(13 \%)$ & $1 / 28(4 \%)$ & $1 / 18(6 \%)$ \\
\hline Recurrence/occult residual & $3 / 110(3 \%)$ & $0 / 31(0 \%)$ & $1 / 35(3 \%)$ & $2 / 44(5 \%)$ \\
\hline \multicolumn{5}{|l|}{ Complications } \\
\hline Overall rate & $22(8 \%)$ & $5(5 \%)$ & $7(10 \%)$ & $10(12 \%)$ \\
\hline Permanent neurological complications & $8(3 \%)$ & $1(1 \%)$ & $2(3 \%)$ & $5(6 \%)$ \\
\hline \multicolumn{5}{|l|}{ Additional treatment } \\
\hline Embolization & $20(8 \%)$ & $10(10 \%)$ & $8(11 \%)$ & $2(2 \%)$ \\
\hline Surgery & $26(10 \%)$ & $3(3 \%)$ & $9(13 \%)$ & $14(16 \%)$ \\
\hline Radiosurgery & $12(5 \%)$ & $6(6 \%)$ & $6(8 \%)$ & 0 \\
\hline
\end{tabular}

* Dural AVF types are defined in Table 1.

\section{Overall Treatment Outcomes}

The overall initial angiographic occlusion rate was $70 \%$; $8 \%$ of partially treated lesions $(6 / 77)$ went on to spontaneously thrombose. Of 183 patients with initially occluded dAVFs, 110 underwent angiographic follow-up over a total of 111 patient-years (mean follow-up 1 year). Of these 110 patients, $3(3 \%)$ had radiographic recurrence of dAVFs that were initially angiographically occluded. The overall complication rate was $8 \%$, with permanent neurological complications in $3 \%$ of cases. Permanent complications included 2 venous infarctions (1 fatal), 3 facial nerve palsies from MMA embolization, 1 middle cerebral artery territory infarction, 1 case of anesthesia dolorosa, and 1 case of worsened ophthalmoparesis after cavernous dAVF embolization.

\section{The Onyx Era}

We treated 87 dAVFs over a 10-year period before the introduction of Onyx into our treatment armamentarium (Table 3). Over the subsequent 10 -year period, we treated 173 dAVFs, with a specific substantial increase in the number of challenging anterior fossa, tentorial, petrosal, and torcular dAVFs. The overall initial angiographic occlusion rate increased significantly from $60 \%$ before the Onyx era to $76 \%$ during the Onyx era $(\mathrm{p}=0.01)$, without a significant change in the complication rate $(p=0.64)$. Among dAVF subgroups, significant improvement in initial angiographic occlusion rates was seen for "high-risk" (Types II-IV) dAVFs $(\mathrm{p}=0.02)$ in the latter period; however, a trending improvement in obliteration rates was seen for all dAVF subtypes. 
TABLE 3. Treatment approaches and results before and during the Onyx era

\begin{tabular}{|c|c|c|c|}
\hline \multirow[b]{2}{*}{ Treatment Approach \& Results } & \multicolumn{2}{|c|}{ No. of Patients (\%) } & \multirow[b]{2}{*}{$\begin{array}{c}p \\
\text { Value* }^{*}\end{array}$} \\
\hline & $\begin{array}{l}\text { Before Onyx } \\
\quad(n=87)\end{array}$ & $\begin{array}{l}\text { Onyx Era } \\
(n=173)\end{array}$ & \\
\hline \multicolumn{4}{|l|}{ Treatment approach } \\
\hline Transarterial only & $37(43)$ & $105(61)$ & 0.008 \\
\hline $\begin{array}{l}\text { Cure via transarterial-only } \\
\text { approach }\end{array}$ & $20(23)$ & $74(43)$ & 0.002 \\
\hline $\begin{array}{l}\text { Cure via single arterial } \\
\text { pedicle embolization }\end{array}$ & $10(11)$ & $50(29)$ & 0.002 \\
\hline \multicolumn{4}{|l|}{ Initial angiographic occlusion rate } \\
\hline Overall & $52(60)$ & $131(76)$ & 0.01 \\
\hline Type I dAVF & $27 / 43(63)$ & $44 / 59(75)$ & 0.28 \\
\hline Type II-IV dAVF & $25 / 44(57)$ & $87 / 114(76)$ & 0.02 \\
\hline Superior sagittal sinus dAVF & $6 / 10(60)$ & $18 / 22(82)$ & 0.22 \\
\hline Cavernous sinus dAVF & $16 / 27(59)$ & $27 / 32(84)$ & 0.12 \\
\hline Tentorial/petrosal dAVF & $10 / 13(77)$ & $31 / 34(91)$ & 0.33 \\
\hline Transverse/sigmoid dAVF & $14 / 28(50)$ & $38 / 57(67)$ & 0.16 \\
\hline Torcular dAVF & $0 / 2(0)$ & $6 / 13(54)$ & 0.47 \\
\hline Marginal sinus dAVF & $3 / 4(75)$ & $7 / 7(100)$ & 0.36 \\
\hline \multicolumn{4}{|l|}{ Additional treatment } \\
\hline Embolization & $4(5)$ & $16(9)$ & 0.22 \\
\hline Surgery & $12(14)$ & $14(8)$ & 0.19 \\
\hline Radiosurgery & $10(11)$ & $2(1)$ & 0.0004 \\
\hline \multicolumn{4}{|l|}{ Complication rates } \\
\hline All complications & $6(7)$ & $16(9)$ & 0.64 \\
\hline Permanent complications & $2(2)$ & $6(3)$ & 0.72 \\
\hline
\end{tabular}

In the Onyx era, there was a significant increase in the proportion of cases treated via transarterial-only approaches $(61 \%$ vs $43 \%, p=0.008)$. In addition, when procedures during the Onyx era were compared with those performed before the Onyx era, there was a significantly greater rate of dAVF obliteration via a transarterial-only approach ( $43 \%$ vs $23 \%$, respectively, $p=0.002$ ), as well as significantly more dAVFs obliterated via a single arterial pedicle ( $29 \%$ vs $11 \%$, respectively; $\mathrm{p}=0.002)$. After the introduction of Onyx, re-treatment tended to be via embolization ( $9 \%$ vs $5 \%$ of dAVFs prior to the introduction of Onyx, $\mathrm{p}=$ $0.22)$ and less often via surgery $(8 \%$ vs $14 \%$ of all dAVFs, $p$ $=0.19)$ or radiosurgery $(1 \%$ vs $11 \%, \mathrm{p}=0.0004)$.

\section{"Low-Risk" (Type I) dAVFs}

Our treated cohort of dAVFs with venous sinus drainage without cortical venous reflux was composed of 102 dAVFs associated with pulsatile tinnitus (61\%) and/ or ocular symptoms (42\%) (Table 2, Fig. 1A). The most common locations were transverse/sigmoid sinuses (42\%) and cavernous sinus (40\%). Other locations included marginal sinus (10\%), torcular (5\%), superior sagittal sinus $(2 \%)$, and tentorial/petrosal (1\%). The treatment approach was most commonly transvenous only (41\%). The overall initial angiographic occlusion rate was $70 \%$ (75\% in the Onyx era).
There were 5 procedural complications (5\% of cases): 2 cases of venous infarcts ( 1 causing permanent neurological symptoms), 1 case of sinus thrombosis treated with thrombectomy without long-term sequelae, 1 case of nontarget Onyx embolization into the transverse sinus treated with stenting without long-term sequelae, and 1 case of transiently worsened ophthalmoparesis after embolization of a cavernous dAVF.

Of 62 Type I dAVFs in which the patient presented with pulsatile tinnitus, 51 had at least 1 month of clinical follow-up (82\% follow-up rate; mean follow-up 3 years). Among the 62 patients in this cohort, 59\% had resolution of tinnitus, $20 \%$ had improvement, and $21 \%$ had persistent symptoms. Angiographically occluded fistulas were associated with a greater rate of symptomatic resolution/ improvement of tinnitus compared with partially treated lesions ( $90 \%$ vs $62 \%$, respectively; $p=0.04$ ). Of 43 Type I dAVFs in which patients presented with ocular symptoms, 40 had at least 1 month of clinical follow-up (93\% followup rate; mean follow-up 2 years). Among the 43 patients in this group, $48 \%$ had resolution of symptoms at follow-up, $30 \%$ had improvement, and $22 \%$ had persistent symptoms. Angiographically occluded dAVFs were associated with greater rates of symptomatic resolution/improvement of ocular symptoms than were partially treated dAVFs $(85 \%$ vs $33 \%$, respectively; $\mathrm{p}=0.02$ ).

\section{"High-Risk" (Type II-IV) dAVFs}

In our group of 260 dAVFs, 72 drained into a venous sinus with cortical venous reflux (28\% Type II, Fig. 1B), 53 drained directly into a cortical vein without significant venous ectasia (20\% Type III, Fig. 1C), and 33 drained into a cortical vein with ectasia (13\% Type IV, Fig. 1D). Of these 158 "high-risk" (Type II-IV) dAVFs, 132 had at least 1 month of untreated follow-up from the time of clinical diagnosis before initiation of any treatment. Over 98.3 patient-years, 3 new NHNDs and 5 hemorrhages occurred, corresponding to annual rates of $3.1 \%$ and $5.1 \%$, respectively. The annual clinical event rate was thus $8.1 \%$, increasing to $10.1 \%$ for symptomatic dAVFs (NHNDs or hemorrhagic presentation).

There was a male sex predominance among patients with Type II-IV dAVFs, which was stronger among lesions with direct cortical venous drainage (Type III/IV, $76 \%$ males) than among lesions with sinus drainage and cortical reflux (Type II, 60\% males, $\mathrm{p}=0.04$ compared with Type III/IV) (Table 2). Type III/IV dAVFs presented more commonly than Type II lesions with NHNDs (27\% vs $21 \%$, respectively; $\mathrm{p}=0.46$ ) or hemorrhage $(36 \%$ vs $11 \%$, respectively; $\mathrm{p}=0.0004$ ). Type II dAVF locations were similar to Type I dAVFs, including transverse/sigmoid in $54 \%$ of cases, cavernous sinus in $25 \%$, torcular in $14 \%$, superior sagittal sinus in $6 \%$, and marginal sinus in $1 \%$. Among Type III/IV dAVFs, the most common lesion location was tentorial/petrosal in 53\%. There was no statistically significant difference in male sex predilection, presentation modality, or lesion location between Type III and Type IV dAVFs.

A significantly greater proportion of Type II dAVFs were treated with transarterial-only approaches compared with Type I lesions (49\% vs 30\%, respectively, p = 
0.02), and a significantly greater proportion of Type III/ IV dAVFs were treated with transarterial-only approaches compared with Type II lesions ( $88 \%$ vs $49 \%$, respectively, $\mathrm{p}<0.0001)$. Similarly, embolization via the MMA was performed significantly more commonly among Type II dAVFs than Type I dAVFs (63\% vs $31 \%$, respectively, $\mathrm{p}=$ 0.0001 ) and more commonly among Type III/IV dAVFs compared with Type II dAVFs (79\% vs 63\%, respectively, $\mathrm{p}=0.03$ ). There was no statistically significant difference in the rate of transarterial-only approaches and MMA embolization between Type III and Type IV dAVFs. The overall initial angiographic occlusion rate for Type II-IV dAVFs was $72 \%$; the rate was significantly higher for Type III/IV compared with Type II dAVFs (79\% vs $61 \%$, respectively, $\mathrm{p}=0.01$ ).

\section{Dural AVF Treatment Stratified by Location}

Demographics, treatment approaches, and results are stratified by dAVF location in Table 4. A significant male sex predilection was seen among patients with superior sagittal sinus (75\% males), sphenoparietal sinus (80\% males), tentorial/petrosal (79\% males), torcular (73\% males), and marginal sinus (73\% males) dAVFs. A slight female sex predilection was seen among patients with cavernous dAVFs (58\% females). Pulsatile tinnitus was a common presenting symptom for marginal sinus (82\%), transverse/ sigmoid (80\%), and torcular dAVFs (53\%). Ocular symptoms were commonly seen among cavernous sinus (92\%) and marginal sinus (45\%) dAVFs. NHNDs on presentation were seen in $40 \%$ of tentorial/petrosal, $27 \%$ of torcular, $16 \%$ of superior sagittal sinus, and $12 \%$ of transverse/sigmoid dAVFs. Hemorrhagic presentation was seen for $41 \%$ of superior sagittal sinus, $40 \%$ of sphenoparietal sinus, and $30 \%$ of tentorial/petrosal dAVFs.

MMA supply was seen in all sphenoparietal sinus dAVFs (100\%) and in the vast majority of superior sagittal sinus (97\%), transverse/sigmoid (93\%), torcular (93\%), and tentorial/petrosal (85\%) dAVFs. The occipital artery was the most common supply to transverse/sigmoid dAVFs (96\%); it was also commonly seen among torcular (93\%) and tentorial/petrosal (64\%) dAVFs. As expected, most cavernous sinus dAVFs were supplied via the tentorial artery/inferolateral trunk (88\%). Approximately one-half of tentorial/petrosal (55\%), transverse/sigmoid (53\%), and torcular (47\%) dAVFs had supply from the tentorial artery. All marginal sinus dAVFs were supplied via the ascending pharyngeal artery.

The majority of marginal sinus (91\%), cavernous sinus (69\%), and transverse/sigmoid sinus (51\%) dAVFs drained into a venous sinus without cortical venous reflux (Type I). All 5 treated sphenoparietal sinus dAVFs were Type III. All 6 treated anterior cranial fossa dAVFs were Type III/ IV, as were $98 \%$ of tentorial/petrosal and $81 \%$ of superior sagittal sinus dAVFs. Notably, 5 of the 6 anterior cranial fossa dAVFs were Type IV (83\%). Cortical venous reflux was seen in $67 \%$ of torcular dAVFs.

Transvenous approaches were used for the majority of marginal sinus (82\%) and cavernous sinus (71\%) dAVFs. Transarterial-only approaches were used in all sphenoparietal sinus (100\%, all via the MMA) and in most superior sagittal sinus (97\%; 94\% via MMA), anterior cranial fossa
(83\%, all via ethmoidal branches), tentorial/petrosal (81\%; $77 \%$ via MMA), and torcular (80\%) dAVFs. Embolization was commonly via occipital artery $(87 \%)$ and MMA branches $(80 \%)$ in the treatment of torcular dAVFs.

Excellent initial angiographic occlusion rates were achieved in all sphenoparietal sinus (100\%) and in most marginal sinus $(91 \%)$, tentorial/petrosal (87\%), and superior sagittal sinus $(75 \%)$ dAVFs. Lower initial angiographic occlusion rates were seen for torcular dAVFs $(40 \%, \mathrm{p}=$ 0.02 compared with all other locations) and anterior cranial fossa dAVFs $(33 \%, \mathrm{p}=0.06$ compared with all other locations). Excluding torcular and anterior cranial fossa dAVFs, the overall initial angiographic occlusion rate in the Onyx era was $80 \%$.

Of 85 patients with transverse/sigmoid dAVFs, 68 presented with pulsatile tinnitus; 49 of these 68 had at least 1 month of clinical follow-up (mean 2.3 years). Resolution was seen in $61 \%$ of cases, improvement in $20 \%$, and persistent/worsening symptoms in $18 \%$. Of 59 cavernous dAVF cases, 48 of 54 patients who initially presented with ocular symptoms had at least 1 month of clinical follow-up (mean follow-up 1.9 years). Thirty-five percent had resolution of symptoms at follow-up, $46 \%$ had improvement, and $19 \%$ had persistent/worsening symptoms.

\section{Discussion}

The evolution of our understanding of the natural history and endovascular treatment armamentarium for cranial dAVFs has evolved considerably since the earliest classification scheme and the early endovascular work of Djindjian et al. ${ }^{11,12}$ Beyond drainage into leptomeningeal veins, initially identified by Houser et al. ${ }^{15}$ as a risk factor for an aggressive course, symptomatic presentation and venous ectasia are both recognized as independent risk factors for a more aggressive clinical course. ${ }^{8,13,38}$ Nearly 20 years after Djindjian's classification identified the significance of cortical venous drainage and venous ectasia, ${ }^{12}$ Borden et al. $^{6}$ attempted to extrapolate their scheme to spinal dAVFs. Although few employ the Borden-Shucart classification for spinal dAVFs, most refer to the so-called "Borden" classification of cranial dAVFs (Djindjian Type I-III dAVFs). Merland, Djindjian's pupil, coauthored a paper with Cognard to update the Djindjian classification scheme to stratify Type II lesions and Type V lesions with spinal drainage (Table 1). ${ }^{10}$

The dAVFs without cortical venous drainage (low risk/ Djindjian Type I) may cause debilitating headaches, pulsatile tinnitus, or ocular symptoms. ${ }^{13,31,32}$ Interestingly, we found that although there was no association of age with fistula type, there was a male sex predilection among patients with high-risk dAVFs, particularly Type III/IV lesions (76\% male). On the other hand, in contrast to all other locations, there was a female sex predilection among patients with cavernous dAVFs (58\% females). Given that many patients were referred from other centers, we were able to perform a post hoc analysis of event rates in the interval between initial clinical presentation and our initiation of treatment. Over this period, we found an annualized NHND rate of 3.1\% and a hemorrhage rate of $5.1 \%$ for dAVFs with cortical venous drainage (high risk/Djindjian Types II-IV). These results are similar to those published 
TABLE 4. Demographic, presentation, dAVF angiographic, and treatment information stratified by location for 260 dAVFs

\begin{tabular}{|c|c|c|c|c|c|c|c|c|}
\hline Variable & $\begin{array}{l}\text { Anterior } \\
\text { Fossa } \\
(n=6)\end{array}$ & $\begin{array}{c}\text { Superior } \\
\text { Sagittal } \\
\text { Sinus }(n=32)\end{array}$ & $\begin{array}{l}\text { Sphenoparietal } \\
\text { Sinus }(n=5)\end{array}$ & $\begin{array}{l}\text { Cavernous } \\
\text { Sinus } \\
(n=59)\end{array}$ & $\begin{array}{c}\text { Tentorial/ } \\
\text { Petrosal } \\
(n=47)\end{array}$ & $\begin{array}{c}\text { Transverse/ } \\
\text { Sigmoid } \\
\text { Sinus }(n=85)\end{array}$ & $\begin{array}{l}\text { Torcular } \\
(n=15)\end{array}$ & $\begin{array}{c}\text { Marginal } \\
\text { Sinus } \\
(n=11)\end{array}$ \\
\hline Mean age (SD), yrs & $62(12)$ & $57(16)$ & $66(10)$ & $57(17)$ & $57(17)$ & $57(13)$ & $57(22)$ & $66(8)$ \\
\hline Male/female (\% male) & $\begin{array}{c}1: 1 \\
(50 \%)\end{array}$ & $\begin{array}{c}3: 1 \\
(75 \%)\end{array}$ & $\begin{array}{c}4: 1 \\
(80 \%)\end{array}$ & $\begin{array}{l}0.7: 1.0 \\
(42 \%)\end{array}$ & $\begin{array}{l}3.7: 1.0 \\
(79 \%)\end{array}$ & $\begin{array}{l}1.2: 1.0 \\
(55 \%)\end{array}$ & $\begin{array}{c}2.8: 1.0 \\
(73 \%)\end{array}$ & $\begin{array}{l}2.7: 1.0 \\
(73 \%)\end{array}$ \\
\hline \multicolumn{9}{|l|}{ Presentation } \\
\hline Incidental & $5(83 \%)$ & $5(16 \%)$ & $3(60 \%)$ & $3(5 \%)$ & $11(23 \%)$ & $3(4 \%)$ & $2(13 \%)$ & 0 \\
\hline Tinnitus & 0 & $4(13 \%)$ & 0 & $9(15 \%)$ & $3(6 \%)$ & $68(80 \%)$ & $8(53 \%)$ & $9(82 \%)$ \\
\hline Ocular symptoms & 0 & $3(9 \%)$ & 0 & $54(92 \%)$ & $1(2 \%)$ & $4(5 \%)$ & $2(13 \%)$ & $5(45 \%)$ \\
\hline NHND & 0 & $5(16 \%)$ & 0 & 0 & $19(40 \%)$ & $10(12 \%)$ & $4(27 \%)$ & 0 \\
\hline Hemorrhage & $1(17 \%)$ & $13(41 \%)$ & $2(40 \%)$ & $2(3 \%)$ & $14(30 \%)$ & $6(7 \%)$ & $1(7 \%)$ & 0 \\
\hline \multicolumn{9}{|l|}{ Arterial supply } \\
\hline MMA & 0 & $31(97 \%)$ & $5(100 \%)$ & $22(37 \%)$ & $40(85 \%)$ & $79(93 \%)$ & $14(93 \%)$ & $1(9 \%)$ \\
\hline Occipital artery & 0 & $14(44 \%)$ & 0 & 0 & $30(64 \%)$ & $82(96 \%)$ & $14(93 \%)$ & $5(45 \%)$ \\
\hline Tentorial artery & 0 & $3(9 \%)$ & 0 & $52(88 \%)^{*}$ & $26(55 \%)$ & $45(53 \%)$ & $7(47 \%)$ & 0 \\
\hline Ascending pharyngeal artery & 0 & $1(3 \%)$ & 0 & $3(5 \%)$ & $12(26 \%)$ & $37(44 \%)$ & $3(20 \%)$ & $11(100 \%)$ \\
\hline \multicolumn{9}{|l|}{ Drainage pattern } \\
\hline Venous sinus only & 0 & $2(6 \%)$ & 0 & $41(69 \%)$ & $1(2 \%)$ & $43(51 \%)$ & $5(33 \%)$ & $10(91 \%)$ \\
\hline Venous sinus w/ cortical venous reflux & 0 & $4(13 \%)$ & 0 & $18(31 \%)$ & 0 & $39(46 \%)$ & $10(67 \%)$ & $1(9 \%)$ \\
\hline Direct cortical venous drainage & $1(17 \%)$ & $16(50 \%)$ & $5(100 \%)$ & 0 & $28(60 \%)$ & $3(4 \%)$ & 0 & 0 \\
\hline Direct cortical venous drainage + ectasia & $5(83 \%)$ & $10(31 \%)$ & 0 & 0 & $18(38 \%)$ & 0 & 0 & 0 \\
\hline \multicolumn{9}{|l|}{ Treatment approach } \\
\hline Transarterial w/o transvenous & $5(83 \%)$ & $31(97 \%)$ & $5(100 \%)$ & $10(17 \%)$ & $38(81 \%)$ & $39(46 \%)$ & $12(80 \%)$ & $2(18 \%)$ \\
\hline Transvenous w/o transarterial & $1(17 \%)$ & $1(3 \%)$ & 0 & $42(71 \%)$ & $2(4 \%)$ & $8(9 \%)$ & 0 & $9(82 \%)$ \\
\hline Transarterial \& transvenous & 0 & 0 & 0 & $4(7 \%)$ & $7(15 \%)$ & $38(45 \%)$ & $3(20 \%)$ & 0 \\
\hline Direct puncture in angiography suite & 0 & 0 & 0 & $14(24 \%)$ & 0 & 0 & 0 & 0 \\
\hline \multicolumn{9}{|l|}{ Embolized arterial pedicles } \\
\hline MMA & 0 & $30(94 \%)$ & $5(100 \%)$ & $8(14 \%)$ & $36(77 \%)$ & $54(64 \%)$ & $12(80 \%)$ & 0 \\
\hline Occipital artery & 0 & $1(3 \%)$ & 0 & 0 & $14(30 \%)$ & $35(41 \%)$ & $13(87 \%)$ & 0 \\
\hline Ascending pharyngeal artery & 0 & 0 & 0 & 0 & $2(4 \%)$ & $3(4 \%)$ & 0 & $2(18 \%)$ \\
\hline Posterior meningeal artery & 0 & 0 & 0 & 0 & $2(4 \%)$ & $2(2 \%)$ & $3(20 \%)$ & 0 \\
\hline Other & $5(83 \%)$ & 0 & 0 & $5(8 \%)$ & $1(2 \%)$ & $1(1 \%)$ & 0 & 0 \\
\hline Initial angiographic occlusion rate & $2(33 \%)$ & $24(75 \%)$ & $5(100 \%)$ & $43(73 \%)$ & $41(87 \%)$ & $52(61 \%)$ & $6(40 \%)$ & $10(91 \%)$ \\
\hline Overall complication rate & $1(17 \%)$ & $5(16 \%)$ & 0 & $4(7 \%)$ & $6(13 \%)$ & $5(6 \%)$ & $1(7 \%)$ & 0 \\
\hline Permanent neurological complications & 0 & 0 & 0 & $2(3 \%)$ & $6(13 \%)$ & 0 & 0 & 0 \\
\hline \multicolumn{9}{|l|}{ Additional treatment } \\
\hline Embolization & 0 & $1(3 \%)$ & 0 & $5(8 \%)$ & $1(2 \%)$ & $9(11 \%)$ & $4(27 \%)$ & 0 \\
\hline Surgery & $3(50 \%)$ & $7(22 \%)$ & 0 & $5(8 \%)$ & $4(9 \%)$ & $4(5 \%)$ & $3(20 \%)$ & 0 \\
\hline Radiosurgery & 0 & 0 & 0 & $3(5 \%)$ & 0 & $6(7 \%)$ & $3(20 \%)$ & 0 \\
\hline
\end{tabular}

* Tentorial artery or inferolateral trunk.

in a recent pooled analysis of $395 \mathrm{dAVFs}$ that included 254 lesions with cortical venous drainage, and annual NHND and hemorrhage rates of $4 \%$ and $6 \%$, respectively. ${ }^{13}$ This natural history study also found venous ectasia to be a significant risk factor for hemorrhage, with an annual hemorrhage rate of $21 \%$ for these lesions (Type IV). Minimally symptomatic or asymptomatic dAVF with cortical venous drainage had an annual hemorrhage rate of $2 \%$; this rate increased to $10 \%$ for those associated with NHNDs and to $46 \%$ for hemorrhagic lesions. ${ }^{13}$

\section{Evolution of Treatment}

In parallel with early surgical attempts at arterial ligation, ${ }^{15,17,22}$ the earliest transfemoral endovascular approaches were focused on occlusion of arterial feeders to dAVFs. ${ }^{11}$ Kendall and Logue's ${ }^{19}$ elegant depiction of venous hypertension and the mere need to "disconnect" the fistula in cases of spinal dAVFs helped revolutionize our understanding of this lesion class and is the mainstay of treatment approaches today. Endovascular approaches thus needed to present a way to permanently occlude the fistula 
point. Kerber and colleagues' innovative work with acryl glues paved this avenue, which is still a valuable treatment approach today via NBCA glue embolization. ${ }^{5,20,21}$ Predominantly employing NBCA in their reputable experience with 170 dAVFs, Baltsavias and Valavanis ${ }^{4}$ reported an initial anatomical cure rate of $60.5 \%$ for low-risk and $69 \%$ for high-risk lesions. Permanent morbidity was reported for $2.3 \%$ of cases over a 16 -year period.

Glue embolization, in combination with transvenous approaches for coil occlusion of fistulas, served as the mainstay of treatment approaches during the first half of our evaluated period in this study. Notwithstanding the introduction of Onyx, transvenous coil embolization remained the overall predominant treatment approach for cavernous and marginal sinus dAVFs $(71 \%$ and $82 \%$ of cases, respectively). However, following the introduction of Onyx, there was a significant increase in the proportion of cases treated via transarterial-only approaches $(43 \%$ to $61 \%, \mathrm{p}=0.008)$ and effective angiographic occlusion via transarterial-only approaches $(23 \%$ to $43 \%, \mathrm{p}=0.002)$, in the pre- versus post-Onyx eras, respectively. This reflects the exceptional "pushability" of Onyx that allows considerable penetration and casting of the fistula site, often from a single arterial pedicle ${ }^{1}$ (Figs. 2 and 3).

Considering our transarterial cases, the most commonly embolized pedicle was the MMA (56\% of cases), which reflects its relative proclivity toward easy distal catheterization and preponderant involvement in dAVF supply (74\% of cases had MMA supply). Although it had no significant effect on complications, the introduction of Onyx into the treatment armamentarium had a significantly positive impact on angiographic occlusion rates despite our attempts to obliterate far more challenging dAVFs, including anterior fossa and complex torcular lesions. Indeed, consistent with other series, rates of initial angiographic occlusion of dAVFs with Onyx have roughly approximated $80 \% .^{27,28}$ Similar to our results, one study of 53 patients demonstrated statistically significantly greater rates of occlusion after treatment with Onyx as compared with NBCA. ${ }^{27}$ We intentionally did not compare results between dAVFs treated with Onyx versus those treated with NBCA, but rather between the time Onyx was introduced into the treatment armamentarium and prior to that period. We continue to use NBCA in circumstances of high-flow shunts and fortuitous circumstances of microcatheter wedging that allow for excellent NBCA penetration.

Most dAVF series have focused on rates of angiographic occlusion and recurrence. ${ }^{2,25-28}$ We chose the term "initial angiographic occlusion" rather than "cure" to refer to dAVFs occluded after initial treatment. We reserve the term "cure" to refer specifically to dAVFs with radiographic evidence of persistent vein/fistula casting and persistent angiographic occlusion at least 4 months after treatment on formal complete angiographic evaluation. As Chandra et al. ${ }^{9}$ reported, although short-term recurrence may occur ( $6 \%$ of cases in their series), long-term digital subtraction angiography following short-term digital subtraction angiography revealing occlusion consistently demonstrated durable obliteration (median follow-up 28 months). In contrast to some series, ${ }^{25,26}$ we specifically evaluated the initial angiographic occlusion rate. Providing a total final angiographic occlusion rate after potential
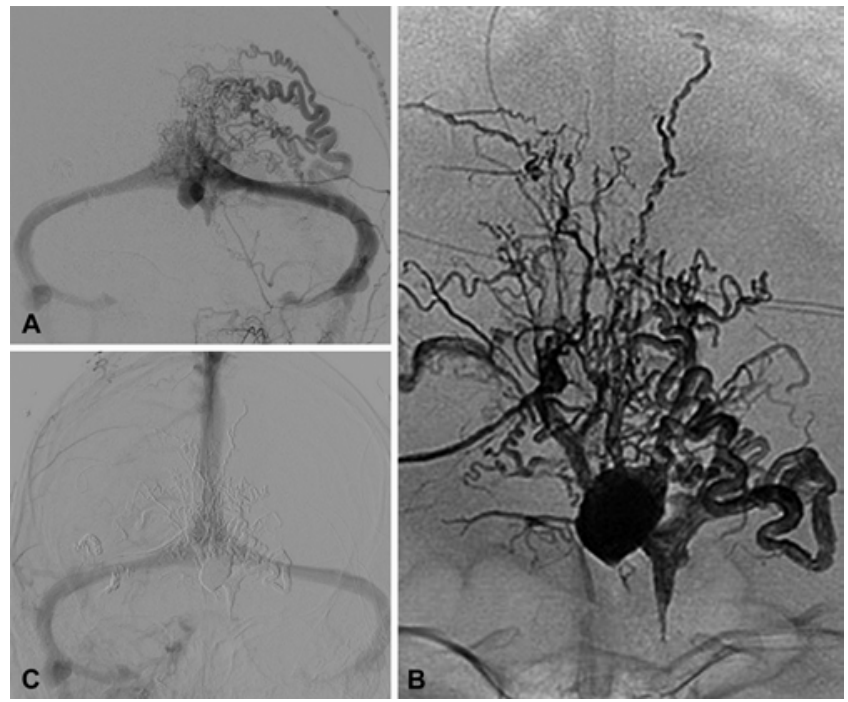

FIG. 3. A complex torcular dAVF (A: anteroposterior view, venous phase of ECA injection) was treated via transarterial Onyx embolization. The Onyx cast demonstrates excellent penetration of the fistula with reflux into the other arterial pedicle (B: anteroposterior view, Onyx cast. C: anteroposterior view, angiographic result).

multimodality therapy is of little clinical value to both the clinician and the patient when initially evaluating a lesion and when counseling on the risks and benefits of a single planned intervention.

We also do not consider dAVFs to be occluded unless the draining vein was casted with an embolizing agent. High-risk cranial (and spinal) dAVFs that are "occluded"/ occult after transarterial treatment without penetration of the draining vein are evaluated for potential further treatment. This approach likely contributes to our relatively low recurrence rate in comparison with some series. ${ }^{2}$ Of 110 initially occluded dAVFs undergoing angiographic follow-up at our institution, we observed 3 cases of recurrent/occult residual dAVFs (3\%). Similar to our results, recurrence was demonstrated in only 1 of 33 cases with angiographic follow-up in a study of 53 patients undergoing NBCA or Onyx embolization of dAVFs. ${ }^{27}$

Of greater clinical value to patients with low-risk dAVFs, we additionally evaluated clinical outcomes with respect to pulsatile tinnitus and/or ocular symptoms after initial endovascular treatment. Although outcomes have been evaluated in only a few reports, our outcomes compare favorably. ${ }^{30,32,33}$ Importantly, we demonstrated that angiographic occlusion was significantly associated with symptomatic resolution/improvement of the respective symptoms, particularly ocular symptoms that only improved in $33 \%$ of partially treated cases. Overall, $59 \%$ of patients had resolution of tinnitus and $48 \%$ had resolution of ocular symptoms. Of clinical significance, tolerable improvement/resolution of tinnitus and ocular symptoms was seen in $79 \%$ and $78 \%$ of cases, respectively; these patients did not undergo further treatment.

\section{Conclusions}

This study demonstrates a significant impact of the in- 
troduction of Onyx on initial angiographic occlusion and the ability to occlude dAVFs via transarterial-only approaches or even a single pedicle. Limitations of our study include its retrospective nature, its single institutional analysis without independent outcome adjudication, and its relatively limited follow-up. Nonetheless, we demonstrate fairly consistent, simple findings that may prove of clinical value when counseling patients: an overall rate of approximately $80 \%$ for initial angiographic occlusion in the Onyx era, and an approximately $80 \%$ rate of meaningful clinical improvement in tinnitus and/or ocular symptoms after treatment. Initial angiographic results should be evaluated with careful scrutiny for effective casting of the draining vein, and delayed follow-up complete angiography must be performed to confirm a true durable angiographic "cure" for high-risk lesions. With more stringent criteria for the declaration of initial angiographic occlusion and subsequent angiographic cure, recurrence after $\mathrm{dAVF}$ treatment is rare.

\section{References}

1. Albuquerque FC, Ducruet AF, Crowley RW, Bristol RE, Ahmed A, McDougall CG: Transvenous to arterial Onyx embolization. J Neurointerv Surg 6:281-285, 2014

2. Ambekar S, Gaynor BG, Peterson EC, Elhammady MS: Long-term angiographic results of endovascularly "cured" intracranial dural arteriovenous fistulas. J Neurosurg 124:1123-1127, 2016

3. Awad IA, Little JR, Akarawi WP, Ahl J: Intracranial dural arteriovenous malformations: factors predisposing to an aggressive neurological course. J Neurosurg 72:839-850, 1990

4. Baltsavias G, Valavanis A: Endovascular treatment of 170 consecutive cranial dural arteriovenous fistulae: results and complications. Neurosurg Rev 37:63-71, 2014

5. Bank WO, Kerber CW, Cromwell LD: Treatment of intracerebral arteriovenous malformations with isobutyl 2-cyanoacrylate: initial clinical experience. Radiology 139:609-616, 1981

6. Borden JA, Wu JK, Shucart WA: A proposed classification for spinal and cranial dural arteriovenous fistulous malformations and implications for treatment. J Neurosurg 82:166179,1995

7. Brown RD Jr, Wiebers DO, Nichols DA: Intracranial dural arteriovenous fistulae: angiographic predictors of intracranial hemorrhage and clinical outcome in nonsurgical patients. J Neurosurg 81:531-538, 1994

8. Bulters DO, Mathad N, Culliford D, Millar J, Sparrow OC: The natural history of cranial dural arteriovenous fistulae with cortical venous reflux - the significance of venous ectasia. Neurosurgery 70:312-319, 2012

9. Chandra RV, Leslie-Mazwi TM, Mehta BP, Yoo AJ, Rabinov JD, Pryor JC, et al: Transarterial onyx embolization of cranial dural arteriovenous fistulas: long-term follow-up. AJNR Am J Neuroradiol 35:1793-1797, 2014

10. Cognard C, Gobin YP, Pierot L, Bailly AL, Houdart E, Casasco A, et al: Cerebral dural arteriovenous fistulas: clinical and angiographic correlation with a revised classification of venous drainage. Radiology 194:671-680, 1995

11. Djindjian R, Cophignon J, Théron J, Merland JJ, Houdart R: Embolization by superselective arteriography from the femoral route in neuroradiology. Review of 60 cases. 1 . Technique, indications, complications. Neuroradiology 6:20-26, 1973

12. Djindjian R, Merland JJ: Super-Selective Arteriography of the External Carotid Artery. Berlin: Springer, 1978

13. Gross BA, Du R: The natural history of cerebral dural arteriovenous fistulae. Neurosurgery 71:594-603, 2012
14. Halbach VV, Higashida RT, Hieshima GB, Mehringer CM, Hardin CW: Transvenous embolization of dural fistulas involving the transverse and sigmoid sinuses. AJNR Am J Neuroradiol 10:385-392, 1989

15. Houser OW, Baker HL Jr, Rhoton AL Jr, Okazaki H: Intracranial dural arteriovenous malformations. Radiology 105:55-64, 1972

16. Hu YC, Newman CB, Dashti SR, Albuquerque FC, McDougall CG: Cranial dural arteriovenous fistula: transarterial Onyx embolization experience and technical nuances. J Neurointerv Surg 3:5-13, 2011

17. Hugosson R, Bergström K: Surgical treatment of dural arteriovenous malformation in the region of the sigmoid sinus. $\mathbf{J}$ Neurol Neurosurg Psychiatry 37:97-101, 1974

18. Hurst RW, Bagley LJ, Galetta S, Glosser G, Lieberman AP, Trojanowski J, et al: Dementia resulting from dural arteriovenous fistulas: the pathologic findings of venous hypertensive encephalopathy. AJNR Am J Neuroradiol 19:1267-1273, 1998

19. Kendall BE, Logue V: Spinal epidural angiomatous malformations draining into intrathecal veins. Neuroradiology 13:181-189, 1977

20. Kerber C: Use of balloon catheters in the treatment of cranial arterial abnormalities. Stroke 11:210-216, 1980

21. Kerber CW, Cromwell LD, Sheptak PE: Intraarterial cyanoacrylate: an adjunct in the treatment of spinal/paraspinal arteriovenous malformations. AJR Am J Roentgenol 130:99-103, 1978

22. Kosnik EJ, Hunt WE, Miller CA: Dural arteriovenous malformations. J Neurosurg 40:322-329, 1974

23. Lasjaunias P, Chiu M, ter Brugge K, Tolia A, Hurth M, Bernstein M: Neurological manifestations of intracranial dural arteriovenous malformations. J Neurosurg 64:724-730, 1986

24. Macdonald JH, Millar JS, Barker CS: Endovascular treatment of cranial dural arteriovenous fistulae: a single-centre, 14-year experience and the impact of Onyx on local practise. Neuroradiology 52:387-395, 2010

25. Natarajan SK, Ghodke B, Kim LJ, Hallam DK, Britz GW, Sekhar LN: Multimodality treatment of intracranial dural arteriovenous fistulas in the Onyx era: a single center experience. World Neurosurg 73:365-379, 2010

26. Piippo A, Niemelä M, van Popta J, Kangasniemi M, Rinne J, Jääskeläinen JE, et al: Characteristics and long-term outcome of 251 patients with dural arteriovenous fistulas in a defined population. J Neurosurg 118:923-934, 2013

27. Rabinov JD, Yoo AJ, Ogilvy CS, Carter BS, Hirsch JA: ONYX versus n-BCA for embolization of cranial dural arteriovenous fistulas. J Neurointerv Surg 5:306-310, 2013

28. Rangel-Castilla L, Barber SM, Klucznik R, Diaz O: Mid and long term outcomes of dural arteriovenous fistula endovascular management with Onyx. Experience of a single tertiary center. J Neurointerv Surg 6:607-613, 2014

29. Rezende MT, Piotin M, Mounayer C, Spelle L, Abud DG, Moret J: Dural arteriovenous fistula of the lesser sphenoid wing region treated with Onyx: technical note. Neuroradiology 48:130-134, 2006

30. Rodrigues T, Willinsky R, Agid R, terBrugge K, Krings T: Management of dural carotid cavernous fistulas: a singlecentre experience. Eur Radiol 24:3051-3058, 2014

31. Satomi J, van Dijk JM, terBrugge KG, Willinsky RA, Wallace MC: Benign cranial dural arteriovenous fistulas: outcome of conservative management based on the natural history of the lesion. J Neurosurg 97:767-770, 2002

32. Shah MN, Botros JA, Pilgram TK, Moran CJ, Cross DT III, Chicoine MR, et al: Borden-Shucart Type I dural arteriovenous fistulas: clinical course including risk of conversion to higher-grade fistulas. J Neurosurg 117:539-545, 2012

33. Shah SB, Lalwani AK, Dowd CF: Transverse/sigmoid sinus 
dural arteriovenous fistulas presenting as pulsatile tinnitus. Laryngoscope 109:54-58, 1999

34. Shi ZS, Loh Y, Duckwiler GR, Jahan R, Viñuela F: Balloonassisted transarterial embolization of intracranial dural arteriovenous fistulas. J Neurosurg 110:921-928, 2009

35. Söderman M, Pavic L, Edner G, Holmin S, Andersson T: Natural history of dural arteriovenous shunts. Stroke 39:1735-1739, 2008

36. Spiotta AM, Hughes G, Masaryk TJ, Hui FK: Balloon-augmented Onyx embolization of a dural arteriovenous fistula arising from the neuromeningeal trunk of the ascending pharyngeal artery: technical report. J Neurointerv Surg 3:300-303, 2011

37. Stiefel MF, Albuquerque FC, Park MS, Dashti SR, McDougall CG: Endovascular treatment of intracranial dural arteriovenous fistulae using Onyx: a case series. Neurosurgery 65 (6 Suppl):132-140, 2009

38. Strom RG, Botros JA, Refai D, Moran CJ, Cross DT III, Chicoine MR, et al: Cranial dural arteriovenous fistulae: asymptomatic cortical venous drainage portends less aggressive clinical course. Neurosurgery 64:241-248, 2009

39. van Rooij WJ, Sluzewski M: Curative embolization with
Onyx of dural arteriovenous fistulas with cortical venous drainage. AJNR Am J Neuroradiol 31:1516-1520, 2010

\section{Disclosures}

Dr. McDougall reports that he is a consultant for ev3 and MicroVention.

\section{Author Contributions}

Conception and design: Albuquerque, Gross, McDougall. Acquisition of data: Gross, Moon. Analysis and interpretation of data: Albuquerque, Gross, McDougall. Drafting the article: Gross. Critically revising the article: all authors. Reviewed submitted version of manuscript: Albuquerque. Statistical analysis: Gross. Administrative/technical/material support: Albuquerque, McDougall. Study supervision: Albuquerque, McDougall.

\section{Correspondence}

Felipe C. Albuquerque, c/o Neuroscience Publications, Barrow Neurological Institute, St. Joseph's Hospital and Medical Center, 350 W Thomas Rd., Phoenix, AZ 85013. email: neuropub@ dignityhealth.org. 